\title{
CARDIAC COMPLICATIONS IN SCARLET FEVER
}

\author{
BY
}

\author{
C. NEUBAUER
}

(From the City Hospital for Infectious Diseases, Newcastle upon Tyne)

Involvement of the heart is not an uncommon complication in scarlet fever. A large amount of clinical material has encouraged this review of the problem of cardiac complications in scarlet fever and in related haemolytic streptococcal infections.

Stegemann (1914) described pathological changes in the myocardium and nervous system of the heart. Siegmund (1931) found inflammation chiefly in the thebesian vessels. Brody and Smith (1936) found pathological changes in the heart of 90 per cent. of the fatal cases. They described three types of myocarditis: 1. Focal or diffuse interstitial myocarditis. 2. Arteritis or periarteritis of the smaller coronary arteries. 3. An infiltration of the coronary veins or of the endocardium of the ventricles. Albert (1938) found myocarditis in four cases among eight children who died of scarlet fever. Toomey (1942) found haemorrhages in the bundle of His in a case of auriculo-ventricular block. Five cases of double infection of scarlet fever and diphtheria were examined by the same author: myocarditis was found in two cases.

Among the clinical reports Nobécourt's paper (1918) must be mentioned; he found two out of seven soldiers who had clinical signs of endocarditis and developed signs of permanent damage in the heart. Thursfield (1929) found carditis especially in cases of scarlet rheumatism and he noticed permanent damage in some of the cases. The cardiac complications due to scarlet fever without scarlatinal rheumatism are regarded by him as temporary and he did not see permanent damage in these cases. Rolleston (1912) noticed a fall in blood pressure in 25 per cent. of the cases after an initial rise in the beginning of the disease. He found (1929) the incidence of endocarditis below one per cent.; myocarditis was more common and this was manifested by rapid and small pulse, feeble heart sounds and gallop rhythm, but no data of its incidence could be given. Stoeber (1935) described his main clinical findings in myocarditis in scarlet fever as: cardiac enlargement, soft systolic apical murmur and arrhythmia. He attributed sudden death in scarlet fever to an acute myocarditis. Wyborn (1934) out of a series of 2,300 cases at the South Eastern Hospital discovered only four cases of arrhythmia, one being a case of auricular fibrillation and the other three just simple arrhythmia. Out of 600 cases of scarlet fever Faulkner (1935) had seven that developed signs of chronic valvular disease. In two of his cases the signs of endocarditis developed in hospital before discharge.
Harries and Mitman (1944) regard the carditis in scarlet fever as identical with that of acute rheumatic fever: in their opinion it is an endocarditis which leaves permanent valvular lesions. Cardiac enlargement was observed by Toomey (1942) in five per cent. of his cases and heart block has been seen in one case during life.

In the present study clinical examination, cardiogram, x-ray photograph and blood sedimentation rate were taken into consideration in arriving at the conclusion whether a heart complication was present or not. The children with a cardiac complication were kept under observation for a period of at least one year after the onset of the acute disease to ascertain the occurrence or non-occurrence of permanent cardiac damage. An attempt was made to differentiate cases of myocarditis from those with endocarditis and from others in which both conditions were present.

\section{Incidence}

There are 602 cases of scarlet fever in the present series observed from August, 1943, till August, 1944. In the majority of the cases the disease was generally of a mild character. On the average cases were discharged during the fourth week of disease. The mild character of the disease can be judged by the incidence of complications occurring. Apart from cardiac complications these were:

$\begin{array}{lrrrrr}\text { Otitis media } \ldots & \ldots & 18 \text { cases } & 3 \text { per cent. } \\ \text { Mastoiditis } & \ldots & 5 \text { cases } & 0.8 & , & , \\ \text { Purulent rhinitis } & \ldots & 68 \text { cases } & 11 \cdot 2 & , & , \\ \text { Adenitis } . & \ldots & 57 \text { cases } & 8 \cdot 1 & , & , \\ \text { Scarlatinal rheumatism } & 4 \text { cases } & 0.6 & , & , \\ \text { Nephritis } . . & . & 3 \text { cases } & 0.5 & , & ,\end{array}$

There were in addition 36 cases of cardiac complication recorded in the present series, that is an incidence of 5.9 per cent.

The ages of the patients with carditis were:

$$
\begin{array}{ll}
0-10 \text { years } & 25 \text { cases } \\
\text { Over } 10 \text { years } & 11 \text { cases }
\end{array}
$$

The history: None of the patients with a cardiac complication had a history of a previous attack of acute rheumatic fever. This is of some importance, because an infection with $\mathrm{S}$. haemolyticus could easily elicit a flare-up of a latent rheumatic carditis. 
Ten of the children, however, had had one acute infectious disease previously, twelve had had two infectious diseases, nine had had three, whilst one child had had four and another five infectious diseases within the last two or three years. Three patients had had no disease before.

The diseases concerned were:

$\begin{array}{llllr}\begin{array}{l}\text { Measles } \\ \text { Pertussis }\end{array} & \ldots & \ldots & \ldots & 30 \text { cases } \\ \text { Chickenpox } & \ldots & \ldots & \ldots & 13 \text { cases } \\ \text { Rubella .. } & \ldots & \ldots & \ldots & 12 \text { cases } \\ \text { Mumps . } & \ldots & \ldots & \ldots & 6 \text { cases } \\ \text { Repeated tonsillitis } & \ldots & \ldots & 4 \text { cases } \\ \text { Bronchopneumonia } & \ldots & \ldots & 5 \text { cases }\end{array}$

\section{Clinical findings}

The heart on admission: Ten cases amongst those who developed carditis in the course of the disease exhibited a marked tachycardia on admission; a soft systolic murmur was audible at the apex in five cases and over the heart base in one case.

Onset of carditis: In more than half of the cases of the present series, the cardiac complications were discovered in the second or third week of the disease. The child was often almost ready for discharge when the first clinical signs were observed.

The onset was observed:

Within the first 10 days of disease 5 cases From 11th-20th day of disease 16 cases

From 21st-30th day of disease 12 cases

Faulkner (1935) examined 171 cases of scarlet fever cardiographically and he could not find any abnormality before the thirteenth day of disease. Such has not been my experience for, in five instances, I found the onset of carditis within the first ten days. As has been reported on another occasion, a myocarditis re-occurs readily in a child who has had a myocarditis previously, especially in a child with a history of several infectious diseases within the last one or two years. In children, however, who had no previous infectious disease or who had one a long time ago, the myocarditis manifests itself towards the end of the second, more often in the third or fourth week of the disease.

This is of some importance:

1. The carditis follows the tonsillitis after a certain interval as in acute rheumatic fever.

2. The carditis occurs at a time when the patient is commonly regarded as being fit to get out of bed.

General signs. Pallor, listlessness, slight cyanosis may be the first signs to indicate a cardiac involvement. The eyes are shadowed. The slightest effort may cause fatigue.

\section{Clinical signs.}

MuRmurs are frequent in children and little reliance can be placed upon them. It is well known that a high temperature or a severe anaemia may be the cause of an apical systolic murmur. In the present series murmurs manifested themselves in the course of the disease as follows:-
Mitral systolic murmur, which disappeared $\quad . . \quad$.. $\quad$.. $\quad$..

Mitral systolic murmur which became permanent $\quad . \quad$.. $\quad$.

Mitral presystolic murmur which became permanent $\quad . . \quad \ldots \quad$..

Cases admitted with systolic murmur, which was permanent $\quad . .6 \quad . .6$ cases

A murmur may disappear and become manifest again. Findlay (1931) in his comprehensive paper on rheumatic infection in childhood found that in a proportion the murmur returned after a period of years. It would be equally wrong to attribute some importance to each murmur as it would be, for example, to disregard all systolic murmurs at the apex. The difficulty lies in the fact that it is not possible to differentiate an organic from a functional murmur on clinical grounds alone; experience has shown that there are good reasons to suspect a carditis if the murmur at the apex is loud and if it has a wide transmission or if a diastolic or presystolic murmur manifests itself.

CARDiac enlargement. A definite enlargement of the cardiac dullness is an important sign of acute carditis. Owing to the enlargement the apex beat is displaced either outward, or outward and downward. This is not a common finding, however, especially in an early case, and it was found in only three cases in the present series. The cardiac dullness is only a little increased in most cases. It will be shown that the cardiac disease occurring in scarlet fever is due as a rule to myocarditis rather than to a valvular disease. Persistent tachycardia, diminished intensity of the first apical sounds are signs of a myocarditis in the early stages of the disease, whereas changes in the rhythm like gallop rhythm or embryocardia occur more frequently in advanced stages. In the present series the first apical sound became markedly diminished in intensity in seven cases; the first apical sound became equal in intensity to the second in two cases; frequent premature beats were found in another case.

The clinical signs subsided after a shorter or longer period:-

$$
\begin{gathered}
\text { Within 3-4 weeks in } 8 \text { cases } \\
, " 5-6 \text { weeks ,, } 6 \text { cases } \\
, " 7-8 \text { weeks ," } 8 \text { cases } \\
, " 9-10 \text { weeks in } 8 \text { cases }
\end{gathered}
$$

After 3 months in 2 cases

, 6 months , 1 case

In some instances, however, a presystolic murmur may persist, it may become an early diastolic murmur later on and a late diastolic murmur after several months. Two cases of this kind have been observed in the present series. In two more cases a mitral systolic murmur developed which became permanent.

THE TEMPERATURE. An increase in temperature after an afebrile period was noticed in seven cases. Clinical signs of carditis were found simultaneously with the increase of the temperature in four cases; the temperature preceded the clinical signs in three cases, whilst the carditis was noticed a few days 
before the temperature rose in three more cases. The febrile period lasted:-

$$
\begin{aligned}
& 3 \text { days in } 2 \text { cases } \\
& 4 \text {, }, 2 \text { cases } \\
& 6 \text { ", } 1 \text { case } \\
& 9 \text { ", } 1 \text { case }
\end{aligned}
$$

THE BLOOD PRESSURE. In diphtheria and typhoid fever myocarditis is nearly always accompanied by a considerable fall in pressure. This is, however, not the case in scarlet fever. Rolleston (1912) found a fall in blood pressure in 25 per cent. of the cases after an initial rise during the febrile period. In the present series the diastolic pressure was found lowered in fourteen cases (38 per cent.), systolic and diastolic pressure was diminished (22 per cent.) in eight cases.

From the signs and symptoms enumerated so far it becomes clear that it is difficult to state whether an acute carditis is present in a case of scarlet fever or not, and why the clinician, because of the absence of recognizable clinical signs of carditis, is often reluctant to accept its diagnosis.

THE BLOOD SEDIMENTATION RATE (B.S.R.). The B.S.R. has been proved to be a test of great value in determining whether a heart disease is acute or not, and in estimating the degree of activity of a cardiac lesion. It stands to reason that an infection with S. haemolyticus might cause an increase of the B.S.R. but the increase in the B.S.R. is greater in a case complicated by carditis than in an uncomplicated case of scarlet fever.

The figure on the left (see fig. 1) shows the curve according to the original Westergren method taken

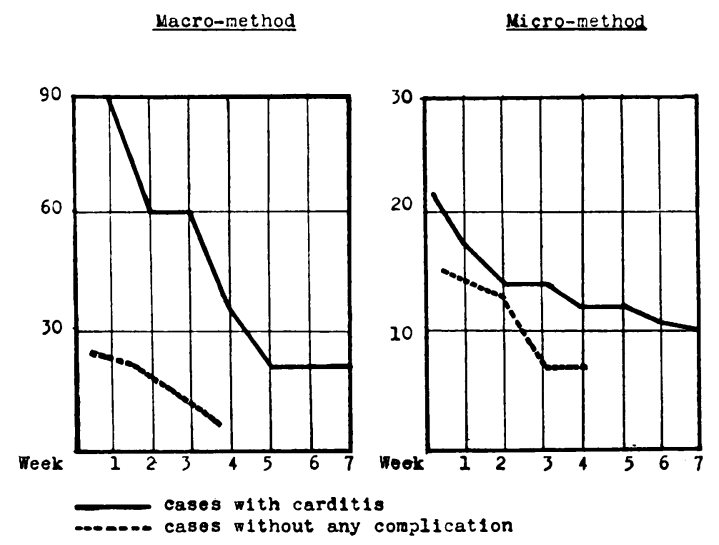

FIG. 1.

from ten cases of carditis, the B.S.R. being 90-100 in the first hour during the first week of the disease, dropping to about 25 after six to seven weeks. The dashed line shows the B.S.R. in ten cases of scarlet fever without any complication taken by the original Westergren method. The difficulty encountered with the Westergren method is that it is not always easy to obtain blood from a child by venaepuncture. Therefore a micromethod was found more convenient, as blood flowing freely from a punctured finger is more easily obtainable. The figure on the right shows a curve, the average B.S.R. of 29 cases of carditis in scarlet fever taken by micromethod. Compared with the first curve it shows that during the acute stages of the carditis the macromethod is more sensitive, giving higher readings. A micromethod for B.S.R. has been used by Cutler (1927), Smith (1936), Benson and Rogers (1941), Trought (1942). It is of definite value in estimating the clinical condition in scarlet fever. It was increased in all instances but two, when the readings were doubtful. But by tests repeated at intervals a useful indication is given of the progress of the carditis. A sudden increase in the B.S.R. over 50 by macromethod or 20 by micromethod is a danger sign, which must not be ignored. The increase of the B.S.R. was found highest in the first and second week of the carditis. It dropped during the third week, remained for a week or so on the same level with either method and dropped in the course of the fifth week, but it was still increased during the sixth or seventh week. In some instances it remained increased for months as in rheumatic heart disease. The dashed line in the right figure shows the B.S.R. of twenty-nine cases of scarlet fever without any complication taken by micromethod. Technical errors can be made with either method. In agreement with Trought it was found that the normal readings of the B.S.R. by micromethod were $2-9 \mathrm{~mm}$. in the first hour. It was found increased up to $14 \mathrm{~mm}$. in moderately severe cases of carditis and up to $30 \mathrm{~mm}$. in very acute cases of carditis.

THE CARDIOGRAM. The increasing use of the cardiograph has lead to rapid advances in knowledge of the diseases of the heart; it is an objective method of examining the heart function. Without a cardiogram an examination of a child's heart cannot be regarded as complete.

The cardiograph was used for investigations in fifty scarlet fever patients first by Shookhoff and Taran (1931). They found changes in the S-T segment in 14 per cent. of the cases and the $T$ wave in 10 per cent. They found furthermore that all abnormalities disappeared in early convalescence. Faulkner et al. (1935) examined by cardiograph 171 scarlet fever cases from 1932-1934 during a relatively mild endemic. They found abnormal records in eleven cases ( 6 per cent.). The auriculoventricular conduction was prolonged in five cases and $T$ wave changes were found in six cases. The $T$ wave changes consisted of marked temporary diminution in amplitude or flattening or inversion.

Cardiograms are not taken in this hospital as a routine, but only if heart disease is suspected. In other words, this study is based on a group of patients who have been selected on the basis of suspected heart disease. In such a case one or more cardiograms were taken during the acute stage of the disease, another during convalescence and in those instances in which recovery was incomplete, the patient was followed up by examinations in monthly or longer intervals after discharge. The common findings in the cardiogram of a carditis were: 1 . The deviation of the S-T segment. 2. The 
flattening or inversion of the $T$ waves. 3 . The voltage of the ventricular deflections was diminished especially in advanced cases of myocarditis. As pointed out before, serial records may be necessary to detect the presence of a carditis. In addition impairment of the auriculo-ventricular conduction manifested by prolongation of the $P-R$ interval occurred, leading to partial A-V block (see case 3, p. 86). The cardiogram may show $P-R$ prolongation without other abnormal findings (see case 4). Frequent premature beats have been observed (see case 5) and also auricular fibrillation (see case 7). Increase in size, notching and widening of the $P$ waves occurred frequently (see cases 2, 5, 6). Following recovery the cardiogram usually returned to normal. This happened in milder cases within six weeks (see case 1): in moderately severe cases within two to three months (see case 2). It is often the best evidence of the subsidence of the active stage of the carditis and in general the patient should not be allowed to get up until the cardiogram has become normal. Occasionally, however, pathological changes may persist or become even more intense after discharge. It is obvious that clinical, cardiographic and laboratory findings have to be correlated to decide whether or not heart disease is present, when it has passed from the acute into the subacute stage and when it has subsided altogether. The diagnosis of a carditis was confirmed by cardiogram in thirty-six cases in the present investigation. There were:-

\section{3 cases of myocarditis \\ 2 cases of partial A-V block \\ 1 case of auricular fibrillation}

The incidence of myocarditis is still disputed. There are clinicians who regard it as common and not particularly serious; there are others who find it a rare clinical condition and of great importance. Our investigations show that myocarditis is not an uncommon complication in scarlet fever and its prognosis is uncertain.

X-RAY EXAMINATION. Examination by $\mathrm{X}$-rays is of great value in determining changes of the size, shape and position of the heart. In some instances it shows enlargement of the heart during the acute stage of the disease, but the enlargement is not well marked. When a permanent valvular damage results the $\mathrm{x}$-ray photograph after several months shows more definite changes, e.g. prominent right border of the heart or a mitral bulge (see cases 6 and 7).

\section{Treatment}

The most important item in the treatment of carditis is to spare the heart unnecessary work. It is advisable to send the child to hospital, if possible. Complete rest should be given and bed-rest continued until the pulse becomes normal, the B.S.R. reaches a normal level and the abnormalities in the cardiogram subside. In doubtful cases it is better to be on the safe side and keep the child in bed a little longer. With prolonged bed-rest the myocarditis will probably subside. Treatment of the original disease with serum, sulphonamide or both has no effect on the complications in scarlet fever. In the present series seven patients received serum, fifteen patients sulphonamide, and two both serum and sulphonamide. Twelve children had no treatment. There can be little doubt that serum treatment has no special influence on the incidence of heart complications.

According to the annual report of the M.O.H., Newcastle upon Tyne, for 1938, there were 662 cases of scarlet fever; 178 were treated with serum, the incidence of complications was 27 per cent. with 0.6 per cent. cardiac complications; 484 cases were treated without serum, the incidence of complications being 28.9 per cent. with 0.2 per cent. cardiac complications. The same applies to treatment with sulphonamides. French (1939) used doses of $5 \mathrm{gm}$. daily for fourteen days and $3 \mathrm{gm}$. daily for the next fourteen days in a carefully controlled investigation in Glasgow. He found no effect on the complications. Wesselhoeft (1942) citing the combined results of four clinical investigations to find out the value of sulphonamide for the prevention of complications in scarlet fever observed no diminution in the incidence of complications among 474 treated cases compared with 587 controls. Furthermore, a combination of the drug with scarlet fever antitoxin in 317 cases brought no diminution in the incidence of complications compared with a similar group of 329 cases treated with serum alone.

The original disease in the present series of thirtysix cases of carditis was mild or moderately severe. This shows the incidence of other complications:-

$\begin{array}{llll}\text { Adenitis } & \ldots & \ldots & 3 \text { cases } \\ \text { Purulent rhinitis } & \ldots & 2 \text { cases } \\ \text { Otitis media } \quad . & \ldots & 2 \text { cases } \\ \text { Nephritis } & \text {. } & \ldots & 1 \text { case } \\ \text { Scarlet rheumatism } & \ldots & 2 \text { cases }\end{array}$

One child died of a double infection with $\mathbf{S}$. haemolyticus and $\mathrm{C}$. diphtheriae on the fifteenth day of disease. The post-mortem examination revealed an acute interstitial myocarditis involving both auricles and both ventricles.

\section{Convalescence}

Experience has shown that the majority of scarlet fever patients make a complete recovery; adolescents and adults often put on weight to such a degree that it exceeds their weight before the illness. In contradistinction to these patients there is another group of children who make a slow recovery and the condition of some of them deteriorates after discharge from hospital. These children are pale, they look anaemic, their appetite is poor, they always feel cold and they easily become tired. Some of them are restless, they do not sleep well; others easily become breathless when going upstairs. Some have a good colour, but they lose it after the slightest effort. The appearance of a slight oedema on the dorsum of the feet is not uncommon. These symptoms and signs have often not been understood and have been misinterpreted as 'secondary' or 'post-infectious' anaemia. The blood investiga- 
tion reveals a hypochromic normocytic anaemia in many instances, but this is one sign of the disease and not the disease itself. In the present investigation these children with cardiac disease were followed up after their discharge from hospital and it was found that the carditis which originated during the acute illness was still present or became even worse after discharge from hospital. The children were brought to the hospital for examination in response to a letter requesting their parents to do so. They can be divided into three groups:-

1. Those who make a complete recovery after several months; the clinical signs subside and the cardiogram returns to normal (see case 1).

2. Those who become better, but the cardiogram shows abnormalities (see case 6).

3. Those who develop a valvular lesion (see case 5).

There were twenty-nine cases belonging to the first group, two belonging to the second group and four belonging to the third group in the present series of thirty-six cardiac complications.

These investigations show that the cardiac complications occurring in scarlet fever are due in great part to myocardial damage. The total incidence, twenty-nine cases out of 602 , was 4.8 per cent. There do not appear to be any reports about the incidence of myocarditis in scarlet fever.

Saphir et al. (1944) in a most comprehensive paper on myocarditis in children found 97 cases of myocarditis amongst 1,420 autopsies of children between the ages of eight days and sixteen years. The incidence was 6.8 per cent. Vischer (1924) found twenty-seven cases of myocarditis in 793 autopsies of children, i.e. 3 per cent. However, as the material investigated by these workers came from general paediatric hospitals, it did not contain many cases of acute infectious disease and their results can not be compared with the present findings.

The incidence of endocarditis in scarlet fever has been studied by several clinicians: Broadbent (1909) found an incidence of 1.8 per cent.; Nobécourt (1918) 2.5 per cent.; Joe (1924) 0.25 per cent.; Rolleston (1929) less than 1 per cent.; McCollum (1925) 1.8 per cent.; Faulkner (1935) 1.1 per cent.
The incidence of endocarditis in the present series was 0.66 per cent.

The clinical and cardiographic findings in endocarditis in scarlet fever are similar to those in acute rheumatic heart disease. Although the etiology of acute rheumatic fever is not known, it is well established that $S$. haemolyticus is frequently associated with acute rheumatic fever. Many investigators believe that $\mathbf{S}$. haemolyticus is etiologically important and possibly the actual cause of the disease. Others have expressed the view that the pathological changes in rheumatic fever are the result of allergy to S. haemolyticus (Swift, Derick, Hitchcock, 1928; Klinge, 1933). The diseases show the following similar points: Sore throat at the onset; carditis manifests itself after two or three weeks, if at all; arthritis common in rheumatic fever, occasional in scarlet fever; increased B.S.R.; the cardiographic and x-ray findings are similar. There is, however, one difference: Aschoff's bodies, accepted by most investigators as specific lesion of acute rheumatic heart disease, have not been seen by the authors mentioned above.

Nowadays scarlet fever is generally regarded as a mild disease, which it certainly is according to the course the disease runs in the majority of the cases and its low mortality. The present investigation shows, however, that heart disease might be acquired in childhood in the course of a mild scarlet fever. It shows, furthermore, how useful it is to see the patient from time to time after his discharge from hospital to ascertain whether the cardiac damage is permanent or not.

\section{ILLUSTRATIVE CASES}

\section{Clinical data and cardiographic findings}

Case 1. A. B., 16 years. Stay in hospital: 11 weeks. Previous disease: Measles.

ON ADMISsion: Severe tonsillitis, rash, C. diph. negative, S. haemol. positive. Nephritis on the 22 nd day of disease. Carditis on the 29th day of disease. Persistent tachycardia, rough systolic apical murmur. B.S.R. $70 \mathrm{~mm}$. in the first hour (macromethod). Discharged with systolic murmur over the heart base and apical region.

CARdiographic Findings: (fig. 2).

FIG. 2.
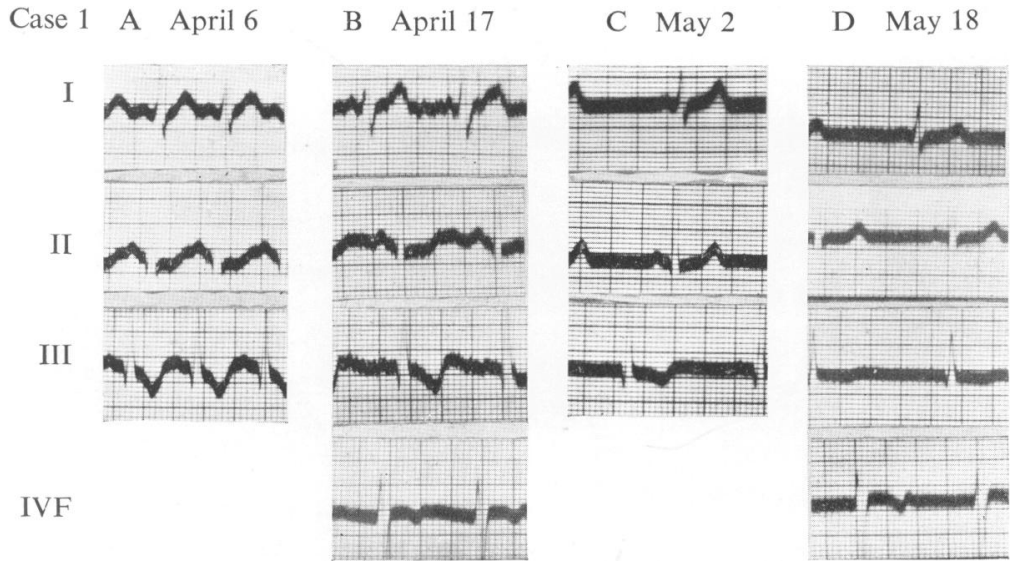


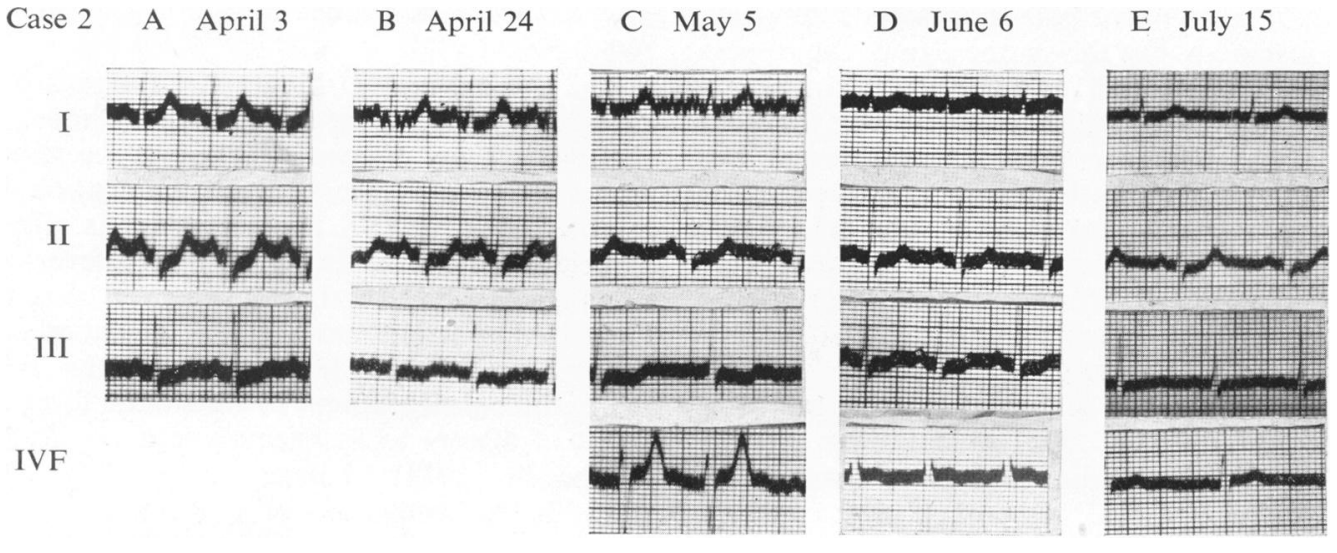

FIG. 3.

RECORD A: Sinus tachycardia, ventricular rate 136 per minute. Right axis deviation, $\mathrm{S}-\mathrm{T}$ segment below the base line in lead II and III. T diphasic in lead II, $\mathrm{T}$ inverted in lead III.

RECORD B: Taken eleven days later, shows more marked right axis deviation, $\mathrm{S}-\mathrm{T}$ segment dislocated in lead II and III. T wave diphasic in lead II and inverted in lead III and lead IV.

RECORD C: Taken one month after the onset of the carditis: Right axis deviation $T$ wave upright in lead II and less inverted in lead III.

RECORD D: Taken seven weeks after the onset of the carditis, the right axis deviation is subsiding and the findings are normal. A diphasic $T$ wave in lead IV may be seen in healthy adolescents.

Case 2. A.G., 12 years. Stay in hospital: 46 days. Previous diseases during the last three years: measles, chickenpox, pertussis, pneumonia. On the 12th day of disease cardiac signs, enlargement of the cardiac dullness, systolic apical murmur. Four weeks after discharge, pale, easily tired, 'weak in the ankles.'

\section{Cardiographic Findings (fig. 3).}

RECORD A: Sinus tachycardia, ventricular rate 150 per minute. S-T transition below the base line in all three leads. $\mathbf{P}$ wave peaked in lead II.

RECORD B: Taken three weeks later. Ventricular rate 120 per minute. $S-T$ segment below the base line in lead II and III. $P$ wave peaked in lead II. $\mathrm{T}$ waves have become smaller.
RECORD C: Taken one month after onset of the carditis. S-T segment below the base line in lead II and III. $T$ wave small and round in lead II. $T$ inverted in lead III.

RECORD D: Taken two months after the onset of the carditis, shows the $\mathbf{S}-\mathbf{T}$ segment depressed in lead I and II, S-T below the base line in lead III, $T$ wave has become flatter in lead $I$, smaller in lead II and diphasic in lead III. The QRS is down and the $T$ wave inverted in lead IV.

RECORD E: Taken four months after the onset of the carditis: $\mathbf{S}-\mathrm{T}$ still below the base line in lead II and III. S-T depressed in lead I. The T wave has become upright in lead IV.

Case 3. J. M., 11 years. Stay in hospital 35 days. Previous diseases: measles, pertussis. Signs of carditis on the 27 th day of disease, systolic apical murmur, highly increased B.S.R. Two months later: easily tired, 'weak on his legs.' Apical murmur less intense.

\section{Cardiographic findings (fig. 4).}

RECORD A: P-R 0.27 second. S-T depressed in all three leads. Partial A-V Block of first degree.

RECORD B: Taken five days later, shows a P-R interval of 0.24 second.

In RECORD C, taken three weeks after the onset of the carditis, the $P-R$ interval is normal. $S-T$ segment depressed in lead II, the $T$ wave has become flat in lead II and inverted in lead III.

RECORD D: A follow-up examination two months

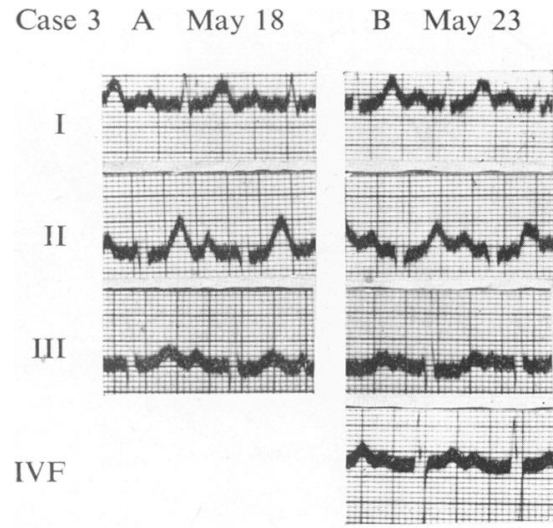

C June 9

D July 21

E $\quad$ Sept. 7
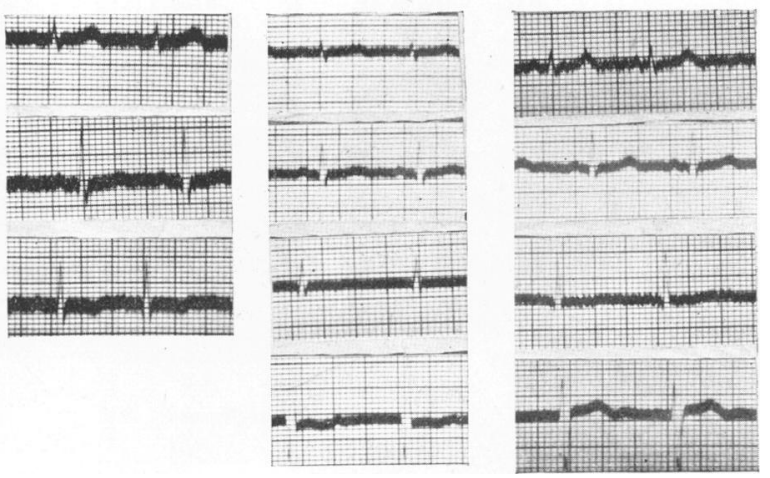

FIG. 4. 


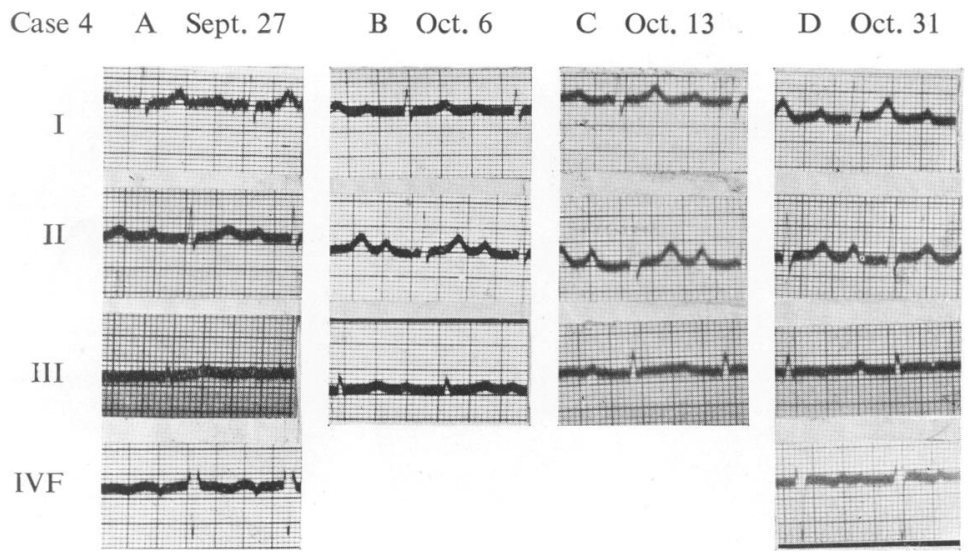

after the onset of the carditis. The voltage of QRS has become diminished, $1.2 \mathrm{mV}$ in all three limb leads together S-T transition depressed in lead II. The $T$ wave has become flat in lead $I$ and inverted in lead IV QRS of Q type in lead IV.

RECORD E: Taken four months after the onset of the carditis is normal.

Case 4. B. M., 15 years. Stay in hospital 40 days. Previous diseases: chicken-pox and measles. Onset of carditis on the 18th day of disease: presystolic apical murmur, high B.S.R.

Cardiographic Findings (fig. 5).

RECORD A: P-R. 0.27 second. No other sign of myocarditis.

RECORD B: 31st day of disease: P-R. $0 \cdot 30$ second.

RECORD C: Three weeks after the onset of the carditis. P-R. $0 \cdot 32$ second.

RECORD D: Taken three weeks later. P-R. 0.29 second.

Case 5. S. F., 11 years. Stay in hospital 54 days. Previous diseases: measles, chickenpox, otitis media. Signs of carditis on the 13th day of disease: systolic apical murmur, frequent premature beats. Two months after discharge still pale: apex beat outside the nipple line, presystolic apical murmur. X-ray: prominent right heart border, prominent pulmonary artery and conus.
CARdiographic findings (fig. 6).

ReCord A: Right axis deviation. S-T transition below the base line in lead II. $\mathbf{P}$ waves peaked in lead I and II.

In RECORD B, taken one month later, the $P$ waves are notched in some cycles of lead I and II S-T segment below the base line in lead II and III. T wave sharply inverted in lead IV.

RECORD C: Taken two months after the onset of the carditis. The right axis deviation has become more marked, the $\mathbf{T}$ wave is flat in lead II. $\mathbf{T}$ inverted in lead III.

RECORD D: Three months after the onset of the carditis. The $T$ waves have become smaller in lead I, flat in lead II, less inverted in lead III.

In RECORD E, taken four months after the onset of the carditis, the heart action is irregular due to premature beats. Right axis deviation. $\mathrm{T}$ wave sharply inverted in lead III.

RECORD F: Taken six months after the onset of the carditis. Right axis deviation. Premature beats of auricular origin. S-T segment depressed in lead I, T wave flat in lead I and II. $T$ inverted in lead IV.

RECORD G: Taken 10 months after the onset of the carditis. Right ventricular preponderance. Premature beats of supra-ventricular origin in lead I, $P-R$. 0.19 second. Slurring of QRS in lead I and III, $P$ diphasic in lead IV, QRS of $Q$ type in lead IV.

D June 10

E July 15

F Sept. 9
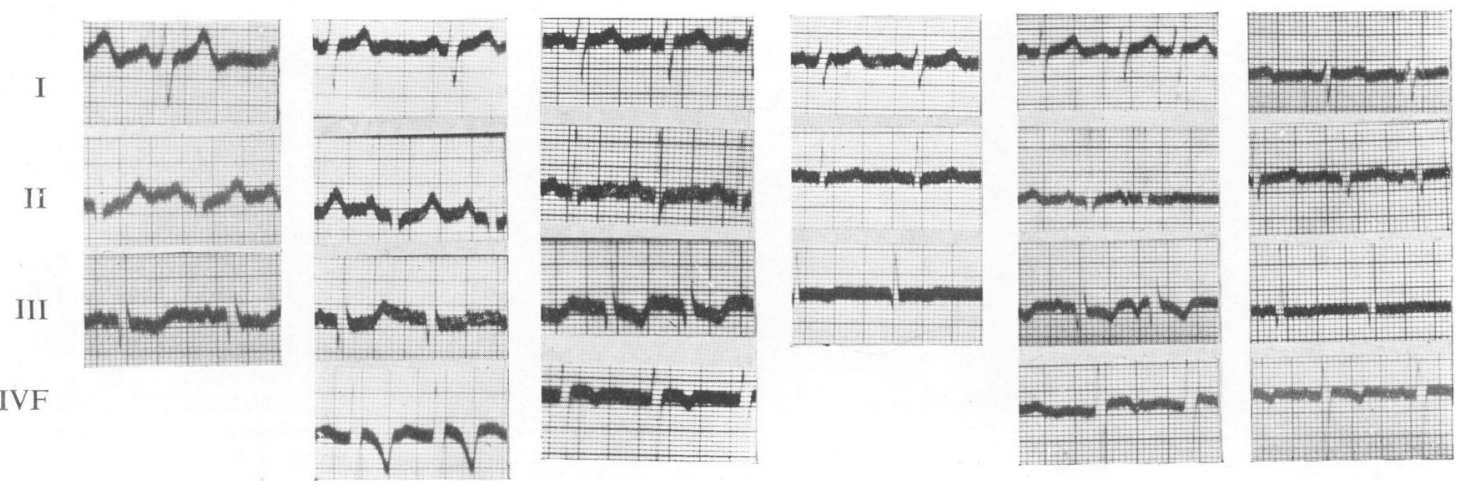

Fig. 6. 


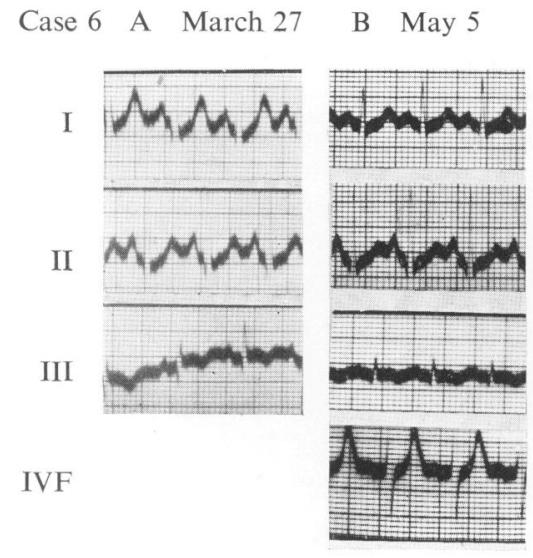

C June 2

D July 29

E Sept. 1

Case 6. J. K., 7 years. Stay in hospital 41 days. Previous diseases: measles, rubella, chickenpox, mumps, pertussis, all of which occurred within the last two years. Onset of carditis on the 16th day of disease. Increased temperature for three days, persistent tachycardia, systolic apical murmur, high B.S.R. Two months after discharge pale, restless, poor sleep. Three months later: soon tired, lost $1 \frac{1}{2} \mathrm{lb}$. body weight in five weeks, poor appetite. Presystolic apical murmur. X-ray taken six months afterwards: right heart border and pulmonary conus prcminent.

\section{CARdiographic FINDINGS (fig. 7).}

RECORD A: Sinus tachycardia, ventricular rate 143 per minute. $P$ waves pointed in lead I and II. $\mathrm{S}-\mathrm{T}$ segment below the base line in lead I and II. $\mathrm{T}$ wave inverted in lead III.

RECORD B: Sinus tachycardia, ventricular rate 159 per minute. S-T dislocated. T has become smaller and round in lead II. $\mathbf{P}$ peaked in lead II.

RECORD C: A follow-up record taken two months afterwards: the ventricular rate is about 150 per minute. Right axis deviation. T flat in lead II, the QRS has become inverted and the $T$ wave much smaller in lead IV.

RECORD D: Taken four months after the onset of the carditis. Right axis deviation. S-T depressed in lead II, T wave flat in lead II.

RECORD E: Taken six months after the onset of the carditis. T wave flat in lead II and IV, inverted

Case 7.

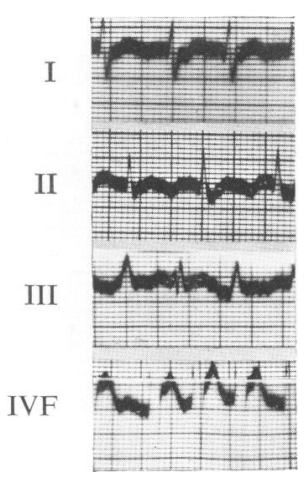

FIG. 8. in lead III. QRS has a small upright phase and is mostly inverted in lead IV.

Case 7. L. A., 5 years. Previous diseases: measles, chicken pox within the last year. C. diphtheriae and $\mathbf{S}$. haemolyticus present in throat swab. Onset of the carditis on the 11 th day of disease. Syncope, gallop rhythm. Died on the 15 th day of disease.

\section{Cardiographic Findings (fig. 8).}

12th day of disease. Action irregular, no $P$ waves are visible. Fine and coarse undulations, unequal in shape, timing and voltage between the ventricular deflections. Auricular fibrillation.

TABLE

THE CARDIOGRAPH FINDINGS IN 110 INVESTIGATIONS

Changes of the $T$ wave

$\left.\begin{array}{llr}\text { flattening } & . & 40 \\ \text { inversion } & . & 4\end{array}\right\} 52$ instances 47 per cent.

isoelectric

S-T segment

$\left.\begin{array}{ll}\begin{array}{l}\text { below the base line } \\ \text { depressed }\end{array} \quad . . & 19\end{array}\right\} 63$ instances 57 per cent.

QRS

of less than $1.5 \mathrm{mV}$ vol-

tage in all three limb-

leads ... .. ..

$5 \quad$.. $18 \cdot 16$ per cent

$P$ wave

peaked, of more than $0 \cdot 3$

mV voltage .. $\quad . .25$ instances 22.7 per cent. right axis deviation .. 46 instances 42 per cent.

P-R prolonged

$\begin{array}{llll}\text { auricular fibrillation } & \ldots & 1 \text { instance } & \\ \text { premature beats } & \ldots & 6 \text { instances } & 5 \text { per cent }\end{array}$ $\begin{array}{llll}\text { tachycardia } & . & \ldots & 15 \text { instances } 13 \text { per cent }\end{array}$

QRS

Chest leads

inverted $\quad . . \quad \ldots 22$ instances 20 per cent. of less than $0.8 \mathrm{mV}$ voltage .. $\quad . \quad \quad \ldots \quad 6$ instances 5 per cent. $\begin{array}{llll}\text { slurring } & \ldots & \ldots & 3 \text { instances } 2 \text { per cent. }\end{array}$ T inverted * $\quad . \quad \ldots \quad 13$ instances 12 per cent

* An inverted $T$ wave might be found in the chest leads of healthy children or adolescents.

N.B. as regards the technique it is understood that all cardiograms have been taken with the patient in the recumbent posture. 


\section{Summary}

1. Thirty-six cases of cardiac complications were observed amongst 602 cases of scarlet fever from August, 1943, till August, 1944.

2. Twenty-nine cases presented as myocarditis; two cases as partial auriculo-ventricular block; four cases as endocarditis; one case died of auricular fibrillation.

3. Clinical examination, blood sedimentation rate, cardiogram and $\mathrm{x}$-ray findings were taken into consideration to ascertain whether heart disease was present or not. A follow-up examination of the patients after their discharge was found useful in arriving at the conclusion whether the cardiac damage was permanent or not.

Thanks are due to Dr. Ian McCracken, Medical Officer of Health, Newcastle upon Tyne, and Dr. G. Hurrell, Medical Superintendent, City Hospital for Infectious Diseases, for facilities provided.

\section{REFERENCES}

Albert, Z. (1938). Now. lek., 50, 565.

Annual Report of the M.O.H. (1938). Newcastle upon Tyne.

Benson, L., and Rogers, E. J. (1914). J. Lab. clin. Med., 26, 987.

Broadbent, J. F. H. (1909). Practitioner, 82, 13.

Brody, H., and Smith, L. W. (1936). Amer. J. Path., 12, 373.

Couper, E. C. R. (1943). Arch. Dis. Childh., 18, 88.

Cutler, J. (1927). Amer. J. med. Sci., 173, 687.

Faulkner, J. M., Place, E. H., and Ohler, W. R. (1935). Ibid., 189, 352 .
Findlay, L. (1931). The rheumatic infection in childhood, London.

French, J. O. (1939). J. Hyg., Camb., 39, 581.

Harries, E. H. R., and Mitman, M. (1944). Clinical practice in infectious disease, 2nd ed., Edin.

Joe, A. (1924). Edinb. med. J., 31, 341.

Klinge, F. (1933) Ergebn. allg. Path. path. Anat., 27, 1.

Master, A. M. (1942). The electrocardiogram and $\mathrm{X}$-ray configuration of the heart, 2 nd ed., Lond.

McCollum, J. H., and Place, E. H. (1925). In Osler's Mod. Med., 1, 764.

Neubauer, C. (1944). Arch. Dis. Childh., 19, 178.

Nobécourt, P. (1918). Bull. Acad. Méd., Paris, 80, 162.

Rolleston, J. D. (1912). Brit. J. Child. Dis., 9, 444. (1929). Acute infectious diseases, 2nd ed., Lond., 271.

Saphir, O. (1941). Arch. Path., 32, 1000. (1942). Ibid., 33, 88.

- Wile, S. A., and Reingold, I. (1944). Amer. J. Dis. Child., 67, 294.

Shookhoff, C., and Taran, L. M. (1931). Ibid., 42, 554.

Siegmund, H. (1931). Verh. dtsch. path. Ges., 26, 231.

Smith, C. H. (1936). Amer. J. med. Sci., 192, 73.

Stegemann, A. (1914). Jb. Kinderheilk., 30, 491.

Stoeber, E. (1935). Arch. Kinderheilk., 105, 193.

Swift, H. F., Derick, C. L., and Hitchcock, C. H. (1928). Trans. Ass. Amer. Phys., 43, 192.

Thursfield, H. (1929). In Garrod, A. E., Batten, F. E., and Thursfield, H. Diseases of children, 2nd ed., Lond.

Toomey, J. A. (1942). In Brennemann, J., Practice of pediatrics.

Trought, H. (1942). Arch. Dis. Childh., 17, 136.

Vischer, M. (1924). In Abhandlung aus der Kinderheilkunde, 2.

Wesselhoeft, C. (1942). In de Sanctis, G., Advances in pediatrics, 1, 95 .

Westergreen, A. (1926). Amer. Rev. Tuberc., 14, 94.

Wyborn, J. T. (1934). Med. Supp. L.C.C. Ann. Rep., 4, pt. 3, 20 . 